\title{
Sustainably Managing Reservoir Storage: Ancient Roots of a Modern Challenge
}

\author{
G. Mathias Kondolf ${ }^{1,2,+}$ (iD) and Alan Farahani ${ }^{3, *,+}$ \\ 1 Department of Landscape Architecture \& Environmental Planning, University of California Berkeley, \\ Berkeley, CA 94720, USA; kondolf@berkeley.edu \\ 2 Collegium-Lyon Institute for Advanced Study, University of Lyon, 24 rue Jean Baldassini, Allée A-2nd Floor, \\ 69007 Lyon, France \\ 3 Cotsen Institute of Archaeology, University of California, Los Angeles, CA 90095, USA \\ * Correspondence: alanfarahani@ucla.edu \\ + These authors contributed equally to this work.
}

Received: 30 September 2017; Accepted: 11 January 2018; Published: 29 January 2018

\begin{abstract}
Sedimentation is a major issue for water systems worldwide, but the need for sustainable sediment management is rarely addressed. This article surveys the problem of sedimentation in the contemporary sphere in addition to drawing on archaeological evidence of past unsustainable and sustainable sedimentation management practices. A compact characterization scheme is presented for identifying the scale of sedimentation management, both past and present. The results of the research illustrate that communities have grappled with issues of sedimentation for as long as water storage has existed. System failure from sedimentation is therefore not inevitable, but arises from a combination of social and biophysical factors.
\end{abstract}

Keywords: sustainability; reservoirs; sedimentation; archaeology

\section{Introduction}

Rivers carry not only water, but also sediment. While most sediment moves suspended in the water column by turbulence (mud, silt, and sand), larger particles can move along the bed by rolling, sliding, and bouncing (the "bedload", consisting of sand and gravel) [1]. By impounding water, dams induce the deposition of sediment, interrupting the natural continuity of sediment transport [2]. Sedimentation is a major concern for water storage systems world-wide. It is a particularly acute problem above dams, which can accumulate vast amounts of sediment depending on the size of the reservoir and sediment yield of the upstream catchment. Dams typically trap $100 \%$ of bedload and a percentage of suspended load that depends on the ratio of the reservoir storage capacity to the river's mean annual flow [3]. As they fill with sediment, the functions of the reservoir are compromised, and eventually storage capacity can be entirely lost.

Small dams, such as those built to supply water to mills, were ubiquitous in the landscape of the eastern United States into the 19th century, when their functions were gradually supplanted by other sources of power [4]. Most of these dams were destroyed or filled with sediment, and those remaining are typically of such small scale that they can now be removed (e.g., to improve passage for fish and recreational boaters) with only minor concerns over the release of accumulated sediment. However, when larger dams fill with sediment, they can present safety risks from dam breaches (which can be triggered by large floods, earthquakes, or structural deterioration [5]), and decommissioning costs can be high [6], as illustrated by the 2015 removal of the San Clemente Dam on the Carmel River, California, which cost at least $\$ 83$ million USD (http:/ / www.sanclementedamremoval.org/?page_id= 1045, accessed October 2017). Increasing awareness of problems posed by the loss of storage capacity in reservoirs has been reflected in recent efforts to better account for sedimentation in the management 
of dams [5,7], including an initiative by the Global Solutions Group on Hydropower and Dams of the World Bank, which produced a 2016 report "Extending the Life of Reservoirs: Sustainable Sediment Management for Dams and Run-of-River Hydropower" [6] and the US National Reservoir Sedimentation and Sustainability Team (a group of US federal agencies, academics, and consultants working to highlight the issue within the US, https:/ /acwi.gov/sos/nrsst/).

In this paper, we consider water reservoir management and sustainable regimes in the human past, and in what ways these examples can provide insight into reservoir management in the present. While modern dams differ in important ways from those built in the more distant and recent past (e.g., changes in the vegetative cover of catchment areas, advances in dam building technologies, and multiple functions of many modern dams), we propose that there are still potentially fruitful comparisons that can be drawn between past and contemporary structures. In particular, we focus on the archaeological evidence for dams and reservoirs in and around the Mediterranean and semi-arid climatic zones of Eurasia, especially the portion extending from the Indian subcontinent to the Iberian peninsula. Mediterranean and semi-arid areas are particularly illustrative because of (a) a rich tradition of archaeological research that has produced a sizeable physical corpus of recovered water supply features; (b) numerous documents left by past societies that allow for greater understanding of the decision making processes related to water supply; and (c) unique environmental challenges presented by these bioclimates, such as a high degree of inter-annual variability in precipitation, which occurs almost solely during the winter months [8].

The archaeological and historical examples presented here indicate that sedimentation seems to have been acknowledged and managed by human communities as long as they have been diverting, storing, and supplying water, which is of particular relevance for current management. Specific sediment management techniques have depended on the methods of diversion and storage employed, in turn reflecting scales and kinds of populations served, the local climate, as well as topographic and hydrologic constraints and opportunities. Finally, the filling of reservoirs with sediment was not inevitable, as some reservoirs have been sustainably—albeit intermittently—managed until the present.

\section{Accounting for Sediment in Dam and Reservoir Design}

In contemporary dam planning and design, a "design life" of 50-100 years is commonly assumed, over which the costs and expected financial returns are calculated $[5,6]$. Sediment is commonly accounted for (if at all) simply by designing "dead storage" sufficient to absorb the anticipated sediment load over the reservoir's design life. Even if the costs of future sedimentation and decommissioning were considered, they would typically be rendered trivial by the application of a discount rate, which reduces future costs and benefits in comparison to the present $[7,9]$. The flurry of dam building that occurred globally since the Second World War has reflected this short-term perspective, as these dams have not included decommissioning costs in their cost-benefit analyses, nor have they addressed the loss of reservoir capacity over time from sedimentation. The concepts of sustainability and intergenerational equity suggest the need for a longer-term view, in which reservoir storage capacity is treated as a non-renewable resource, recognizing that the supply of good reservoir sites is limited [7].

Nevertheless, the vast majority of dams in use on the planet have been built since the mid-20th century, so most dams have existed for less than a century, and thus most have yet to manifest the problems associated with long-term sedimentation. Exceptions are the dams built on rivers with high sediment yields-notably those in geologically active regions such as Taiwan [10] and coastal California [11]. To gain insights into sedimentation challenges over the long-term, we can look back to earlier dams and their potential sustainability.

One of the largest Roman-era masonry dams, near Karyatein, Syria, illustrates the problems of long-term sedimentation, as it filled with sediment many centuries ago, and subsequently breached. In the ensuing centuries, its stored sediment was deeply gullied, but most remained behind the dam as of the late 20th century [5,12]. By contrast, another structure from the Roman-era (first or second century CE)—the Prosperina Dam near Mérida, Spain—still functions. As explained by Morris and 
Fan [5], the $6 \mathrm{Mm}^{3}$ reservoir had a large storage capacity relative to its watershed area: it receives direct runoff from only $7 \mathrm{~km}^{2}$, and the water filling it comes via small canals that divert flow from an additional $13 \mathrm{~km}^{2}$. Thanks to the gentle topography and lack of land disturbance in the catchment, and the fact that the small canals cannot convey large flows during the high flows that carry most sediment, the reservoir was spared serious sedimentation problems and continued to function (with recent maintenance in the 1990s). Such extended service without sedimentation problems is unusual, and is attributable largely to the favorable siting and design. In other cases, ancient dams have continued to function by the active management of sediment, such as the so-called "Spanish Method" of periodically flushing fine sediments, as was implemented in the Almansa Dam (built in 1384 and operating continuously since) in Alicante, Spain, whose $>3 \mathrm{~m}^{2}$ low-level outlet allowed accumulated sediments to be scoured downstream $[5,13]$.

The Spanish method of flushing exemplifies one of many possible strategies to sustainably manage sediment in river systems. As detailed by Morris and Fan [5], Wang and Hu [14], Sumi et al. [15], Annandale [7], and Kondolf et al. [16], there are many approaches to reducing sediment accumulation in reservoirs, some better adapted to certain conditions than others. The best way to manage sediments is to avoid accumulation in reservoirs in the first place, by passing sediment around or through dams. A sediment bypass diverts part of the incoming sediment-laden waters into a tunnel around the reservoir, so they never enter the reservoir at all, but rejoin the river below the dam. An off-channel reservoir can avoid sedimentation if water is diverted to it from the mainstem only during lower flows, when water is relatively sediment free, and modest sediment load is induced to settle out in a sedimentation basin before it enters the off-channel storage site. During high flows, sediment-laden waters are allowed to pass by in the main river undiverted.

There are several other ways to prevent or mitigate early sediment accumulation. Sediment sluicing involves maintaining sufficient velocities through the reservoir to pass sediment without allowing it to deposit, as intended in the design of the Three Gorges Dam on the Yangtze River [14]. In contrast, drawdown flushing scours and re-suspends deposited sediment from the reservoir, and transports it downstream. It involves the complete emptying of the reservoir through low-level gates. Density current venting involves opening dam outlets when turbidity currents pass through the reservoir so that they can remain intact and exit the reservoir via the outlets, carrying most of their sediment with them, a technique well-developed in some reservoirs in China, such as Xiaolanqi Dam on the Yellow River [14]. Mechanical removal in a drawn-down reservoir can be done with scrapers, dump trucks, and other heavy equipment, or if the reservoir is not drawn down, by dredging using hydraulic pumps on barges with intakes [16]. In some cases, such as the Three Gorges Dam, sand and gravel are excavated from the delta, which provides a source of construction aggregate and also helps to reduce the rate of coarse sediment accumulation in the reservoir to some degree. Where dams are built in series (often termed "cascades"), such as the series of mainstem dams on the Lancang River in China, the sediment supplied to downstream reservoirs is reduced, though tributary inputs of sediment in between reservoirs can still create problems in downstream dams.

The reservoir sediment management classifications of Morris and Fan [5] and Kantoush and Sumi [17] both distinguish among three broad categories of management approaches that include the methods discussed above: those that route sediment through or around the reservoir, those that remove sediments accumulated in the reservoir to regain capacity, and those that minimize the sediment arriving to reservoirs from upstream, as illustrated in Figure 1 [16]. The flushing approach used to maintain reservoir capacity of the Almansa Dam would be considered as "drawdown flushing" in the sixth (farthest-right) column in Figure 1. The Prosperina Dam exemplifies the "off-channel reservoir" approach (third column of Figure 1), whereby sediment-laden flows were allowed to pass undiverted from most of the drainage area. A related approach —on a much smaller scale-is exemplified by the "flood trap" at Bir Huweinel at the bottom of Ras as-Slimane, in the Nabataean city of Petra, where flood waters were diverted into a cistern after traversing a 9-m-deep decanting basin designed to settle out sediment, and from which sediment could be cleaned out after the flood [18]. 
The Bir Huweinel approach included components of both the "trap sediment above reservoir" strategy (second column) and the "off channel" strategy (third column). In general, flushing is effective in reservoirs that impound less than $4 \%$ of mean annual flow of the river, and methods such as flushing, sluicing, and sediment bypasses are not suitable for all damsites. Nonetheless, it is striking how rarely these proven technologies are implemented in modern dam construction [7].

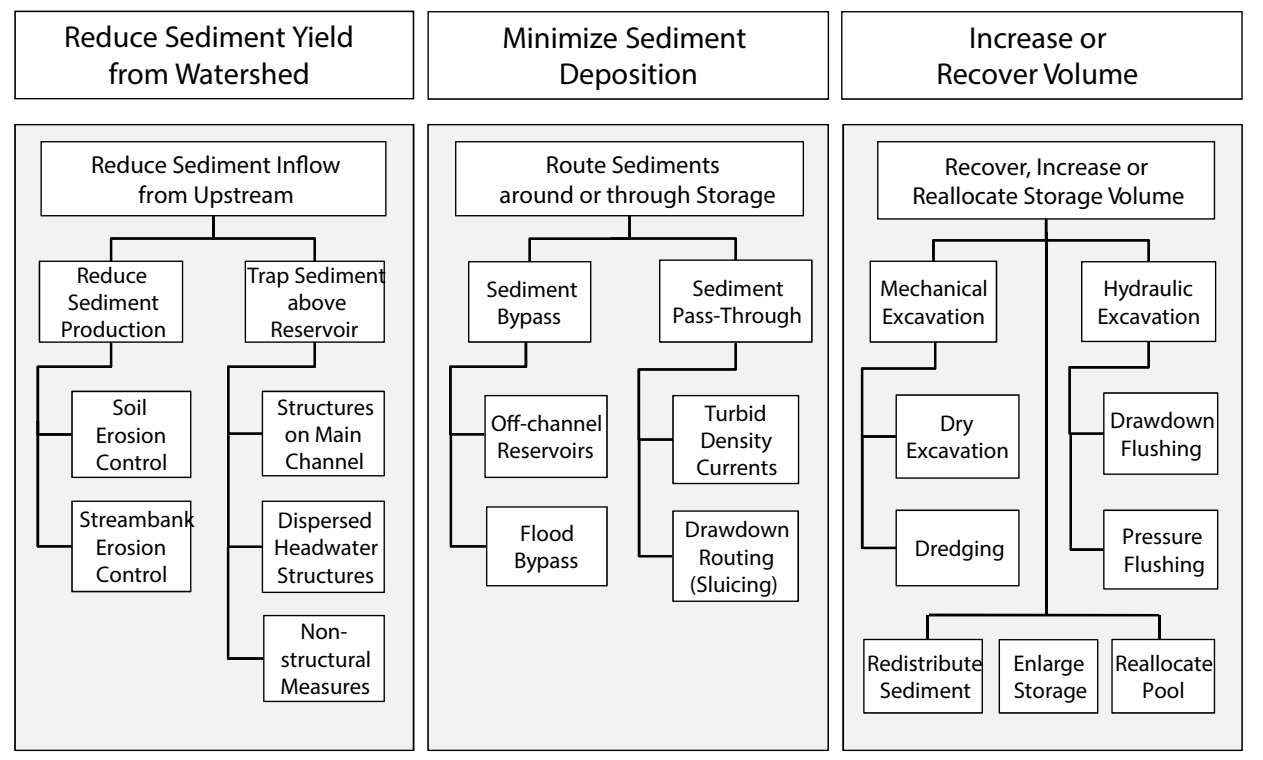

Figure 1. Sustainable sediment management strategies, as categorized by Morris and Fan [5] and Kantoush and Sumi [17].

\section{Water Supply Technologies in the Past}

As mentioned in the examples above, communities have stored and manipulated water for the purpose of supply for several thousand years world-wide [19]. In the Mediterranean basin there is evidence of early sustained water capture from the Neolithic (ca. 9000 BCE) to the present, with some of the earliest evidence from the island of Cyprus ([20], cf. [21-24]). Nevertheless, there has been significant variability in the factors that influenced the creation and maintenance of water supply systems. This includes where communities have chosen to site water engineering structures, why they have chosen to capture or supply this water, how they chose to do so, and when these practices first began to appear. Apart from the specific social and cultural configurations of these communities that influenced the organization of their labor, there were also biophysical factors that exerted equal influence on where and how water was stored and supplied. This included site topography, depth of soil, local hydrology and water sources, and precipitation [19,22]-many of which are noted above in the case of the Prosperina Dam.

Therefore, the social and environmental factors that led to the development of water supply structures were-and are-interdependent, and are most productively approached from a socio-environmental perspective. These perspectives recognize the relative weight of the sociocultural and biophysical variables that affect human communities' ability to construct and maintain (among other things) water supply structures [25]. For example, understanding the construction and placement of dams throughout the Roman Mediterranean (ca. 200 BCE-500 CE) means not just identifying the specifics of the engineering that underline the masonry, outlets, and shape of the structures [26], but also the social logic of the stakeholders who determined which locations were valuable, the hydrology of the areas, and the properties of local soils and sediments ([27] cf. [28]). Moreover, water supply structures became more prominent with the increasing incorporation of domesticated plants into food production and the corresponding need to provide water to them during critical moments of their growing periods. Even then, reservoirs and especially dams are only found in abundance with the advent of more 
sedentary village-based and urban settlements $[19,22]$. Accordingly, the following discussion will focus more on the latter communities, which are often referred to in the archaeological literature as "complex" societies.

In pre-industrial "complex" societies, there appear to be several factors that influence the nature and scale of reservoir and dam construction. These are the degree of urbanism, or the density of nucleated settlements [22], the size of the human (and non-human animal) population served, which is often highly correlated with density of settlements [29], and the degree to which a population was dependent on agriculture and/or animal husbandry [20]. It is possible to envision these factors as situated on a continuum. For instance, the smaller Early Bronze Age societies of the eastern Mediterranean coast (ca. 3000 BCE) contained relatively less urban and dense populations [30], with more than half of their dietary intake derived from agriculture on one end, to the enormous and densely populated cities of Mesoamerica such as Tenochtitlan (ca. 1300-1500 CE) that were entirely dependent on agriculture [31], on the other.

The population densities, settlement patterns, and agricultural intensification schemes that characterized the socio-environmental dynamics of these communities were not static, but fluctuated throughout the past ten thousand years [32,33]. Syntheses of climatological, paleohydrological, pollen, and archaeological evidence in the Mediterranean basin reveal alternating wet and dry climatic episodes, with humid and aridifying periods over thousand-year cycles, in a geographic arc stretching from Spain to Lebanon [34]. Recognizing the dynamic variability of these factors-particularly through time - is one way in which to avoid simplified uni-lineal histories that view the development of water supply practices as necessarily from "simple" to "complex", and from "small-scale" to "large-scale". Instead, a socio-environmental approach encourages those searching for sustainability in past water supply systems to identify the specific contexts that characterized them, whether they are temporal, geographic, social, or environmental [25].

\subsection{Water and Storage Intensification in the Mediterranean and West Eurasia}

Although there are relationships between agricultural production, human population, settlement organization, and large-scale water distribution in many "complex" societies, this does not necessarily support Karl Wittfogel's well-known "Hydraulic Hypothesis" [35]. Wittfogel argued that the construction of irrigation and reservoir structures for intensive agricultural production also necessitated a "despotic" political body to oversee and manage the infrastructural needs of such a complex system. Numerous empirical studies from several parts of the world have falsified this hypothesis, including Mesopotamia [36], Yemen [37], the Andes [38], and East Africa [39]. There are some positive assessments of some of the general correlative claims of this hypothesis [40,41], however, in that most large-scale reservoir and damming operations have been organized by agricultural state societies usually accompanied with a high degree of sedentism. [19] The latter includes the large-scale engineering projects of the Romans and the Inca, both of whom dealt with water engineering issues on a wide geographic, social, and environmental scale [26,42].

The history of the development of water supply practices in the greater Mediterranean basin is particularly instructive due to a rich corpus of well identified and dated structures alongside the availability of written media, in some places, that provide insight into the social logic of decision making, maintenance, and construction. Within this large temporal and geographic span, it is arguable that there are several distinct moments of water storage practice which occur after the adoption of agriculture. Although there is evidence of water supply structures during the early Neolithic in southwest Asia (i.e., during the period when agriculture was gradually adopted ca. 10,000-6000 BCE), this is primarily in the form of wells, such as at Sha'ar Hagolan, located in the State of Israel [43], whose placement has been attributed to "accidents of local geography" [21] (334) or otherwise attributed to "ritual uses" [20] due to the evidence of the intentional deposition of human bodies within the well.

Nonetheless, the first relatively uncontroversial period of the sustained creation of dams begins during the fourth millennium BCE in southwest Asia, close to the eastern Mediterranean littoral [21]. 
This is exemplified by the remains of what have been argued to be incipient villages or semi-sedentary meeting points, represented best by the archaeological sites of Jawa in northeast Jordan and Khirbet al-Umbashi in southern Syria. The communities of both of these areas created dams for the purpose of water storage and supply [44].

Dams and reservoirs designed to impound and re-supply water at the small-to-medium spatial scale seem to have served communities around this broader area for quite some time until the emergence of large-scale empires. It is during the period in which empires begin to proliferate that enormous damming and water diversion operations impounded millions of cubic liters of water to feed huge cities with tens of thousands of people and the plants and animals upon which they depended [45]. Many of these features are still visible on the landscape, and many were utilized until relatively recently. The last of the major phases in dam and reservoir construction in this region occurred only very recently, in the mid and late 20th century as discussed above, when these structures were supplanted by more industrialized forms of water capture and supply [46,47]. In many cases, these new dam constructions were orders of magnitude larger than those that had been previously built, and with rising urban density, failures of sediment-filled dams near these heavily inhabited areas will pose greater threats to human life.

\subsection{Toward a Taxonomy of Ancient Water Reservoirs}

During each of these major moments in the history of water storage and supply, the scale of operation of reservoir and dam systems was highly variable. There were water storage and supply systems that required a considerable amount of human intervention, such as those that involved physically scraping out and removing accumulated sediments (the third option in Figure 1). There were also systems designed to independently agitate sediment in order to lessen the amount of physical intervention needed in cleaning (the second option in Figure 1). Many archaeological sites around the world provide evidence of the independent creation of these kinds of sediment-management strategies in dams and reservoirs. This geographic and temporal breadth in design provides the evidence of success in the design of these systems and also their failure due to breaches caused by the accumulation of sediment. Recognizing the failures of these systems through time is a critical factor in understanding their sustainability or lack thereof [48].

To better understand these water storage systems, we offer a taxonomy of past water storage and supply that includes structures such as reservoirs and dams, but excludes smaller-scale structures like cisterns and basins.

There are already several taxonomies that classify the observed variability in water redirection and storage structures in the past. For instance, Beckers et al. [49] proposed a taxonomy of water storage for the Mediterranean and western Asia that focuses on what they call "autogenic" water supply techniques, that is locally generated water by rainfall, runoff, and intermittent flooding. Another survey of water management in nonindustrial complex societies by Scarborough [19,22] identified four different types of "major earth-moving investments": wells, reservoirs, dams, and canals-the latter of which should be analyzed independently, as it is a flow-water scheme rather than a still-water scheme [19]. Both of these perspectives provide a unifying framework for these structures, albeit focusing on different aspects of water capture, storage, or supply. The recombination of elements from these frameworks yields:

1. Wells and "qanats" used for groundwater storage and supply

2. Terraces and diversion dams used in floodwater and high precipitation event water harvesting and redirection

3. Reservoirs and impoundment dams used for surface water storage and supply

4. Canal systems used to redirect and supply existing water capacities

Within these categories, reservoirs and dams are located on the furthest end of the spectrum of labor and material investment. Accordingly, sedimentation within these systems contains scalar 
and temporal properties (Figure 5). Scale is related to the size of the sedimentation basin in terms of surface area; the greater the scale of the storage system, the easier it is to prolong reservoir life and manage sedimentation. Time is the other factor, and is influenced by the frequency of sediment removal required by the water management system. The relationship of scale and time can delay the onset of symptoms associated with sedimentation. Therefore a broad classification focused on issues of sedimentation can serve as a complement to these other taxonomies that identify types of water capture and storage in the past, and provides a framework for the identification of the sustainability of contemporary and past dams and reservoirs.

The first type-small-scale supply systems—only require somewhat infrequent cleaning, often by hand. These include such "flow-through" water transportation infrastructure as qanats, or storage features such as wells. The second-medium-scale systems-use settling basins or other methods to physically postpone the cleaning of sediment (i.e., there is some storage capacity for sediment built into the system). The third and final system is the very-large-scale, which includes reservoirs and dams that utilize large surface areas to mitigate the problem of sedimentation cleaning; in this case, storage is latent in the system. Below is a brief overview of the history and functioning of these systems in the broader Mediterranean and west Eurasia to highlight the longevity and issues associated with each of these systems.

\subsection{Water Supply Systems in the Wider Mediterranean and West Eurasia}

Small-scale water supply systems were common in agricultural communities across west Eurasia through a form of landscape modification known as the qānāt or karēz. These are subterranean water sources that originate in naturally occurring mountain aquifers or the high water tables of the upper parts of alluvial fans. A series of vertical well-shafts are dug that tap into this water source, connected by a subterranean tunnel to transport water downslope to the valley floor by gravity. Gravity also transports sediment to its ultimate area of deposition, which is typically a canal. These systems can extend for several hundred kilometers and can be dug tens of meters deep [50-52]. Data collected on qanats in the recent past have recorded the transport of an average of about 100 liters of water a minute, with some qanats capable of $1500 \mathrm{~L}$ a minute, and they typically extend about $4 \mathrm{~km}$ in length [50]. The archaeological evidence of their use extends back to ca. $1000 \mathrm{BCE}$, although there is some disagreement as to whether they arose in the Iranian plateau or the Arabian Peninsula [53]. Qanats were used in contemporary Iran, for instance, until industrialized water storage via large-scale damming projects was introduced in the 1940s and 1950s [52], and they were used in Syria until large-scale damming projects precluded their use in the 1990s [46]. Cleaning is often necessary in the event of structural failures, as these structures are often dug into softer sediments, but it is a costly endeavor that requires considerable human labor and social coordination $[47,50]$. Most archaeological qanats do not show evidence of failure due to sedimentation considering their almost constant flow, but instead due to a lack of maintenance, without which they quickly become inoperable.

The medium scale of water storage and supply is well represented at the archaeological site of Petra, located in the south of the Hashemite Kingdom of Jordan (Figure 2). Built in the late first millennium BCE, the Nabataean builders of the city of Petra were faced with an environment that produced only $100 \mathrm{~mm}$ of water a year. As a result, the city contained over 200 cisterns and generated over $360 \mathrm{~L}$ of water a day for each individual inhabitant, who may have numbered 20,000 or more during the time of its densest habitation between 150 BCE and 300 CE [54] (107). There is evidence of numerous sediment-settling tanks used in water-diversion to reservoirs that allowed sediment to accumulate in easily accessible areas for manual removal [54] (105), [55] (24-26). Water would be introduced into a primary settling tank via a canal, piping, or other water transport structure, fill the basin, and the spillover of that water diverted into another reservoir. Cleaning of these basins would entail temporarily halting the flow of water into the primary basin to allow for the removal of sediment. Given the large numbers of cisterns present in the city of Petra, the use of settling basins was a solution to reduce the amount of direct human intervention needed, although the scale of water 
storage would increase as the numbers of reservoirs increased, rather than through the enlargement of any one reservoir.

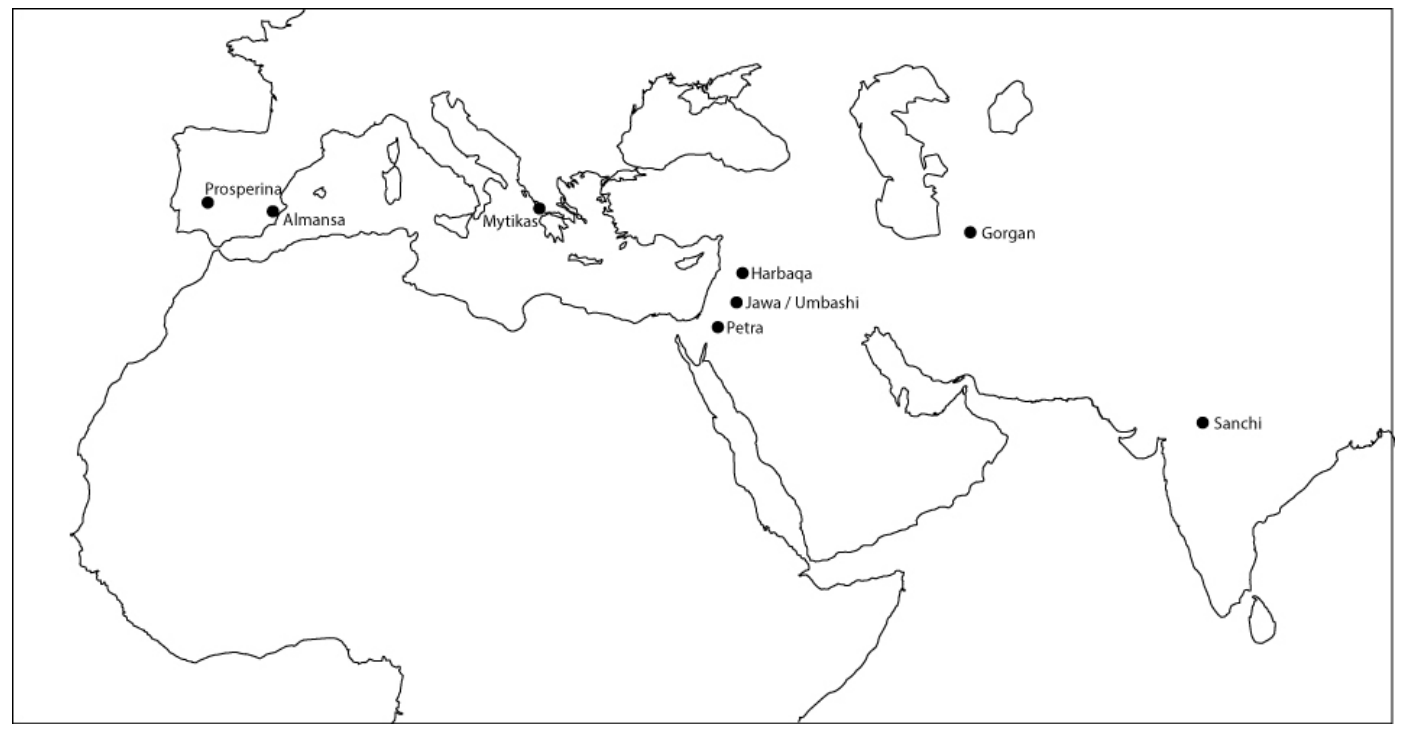

Figure 2. A schematic map of the approximate locations of the dams discussed in this section. Redrawn based on [19].

The large scale is represented by two separate examples, the first and earliest being that of the mid to late fourth millennium BCE site of Jawa in the arid north-east of Jordan, with evidence of both medium-scale flood water management and large-scale reservoir use [56]. An average annual precipitation of less than $100 \mathrm{~mm}$ alone in the area of Jawa could not have supported the population practicing agriculture (numbering no greater than 6000, although there is disagreement as to the maximum total [57,58]), which depended on the reservoirs that were created there [21]. There were several water storage and supply structures-by one estimate totalling 52,000 cubic meters [56] - that drew upon a catchment that could have supplied 2 million cubic meters of water a year [56]. An impoundment dam was built early in the history of the settlement (radiocarbon dated between 3500 and 3000 BCE, [59], see Figure 3) that held back the flow of the nearby Wadi Rajil to impound this water, but it failed due to what appears to be a build-up in sedimentation [60]. Considering the relative novelty of dam construction, which seems to have been aimed at animal and human consumption rather than irrigation, preventing sediment accumulation may not have been a priority of the Jawa community [61]. Indeed, expedient dam constructions for the purpose of water impoundment, again in contrast to water diversion, with subsequent rapid sediment accumulation can be seen elsewhere. Another example is a fourth century BCE dam located on the west coast of Greece, in the Mytikas valley opposite the island of Kalamos. The dam was $11 \mathrm{~m} \mathrm{high,} \mathrm{about} 25 \mathrm{~m}$ long, and was actively fed by a stream about $2 \mathrm{~km}$ away. Despite its relatively robust masonry, one estimate is that it was inoperable due to sedimentation within a decade or two of its construction [62].

While Jawa may represent some of the earliest large-scale damming and reservoir constructions, some of the largest scale operations were overseen in the "imperial period" of the Roman Eastern Mediterranean and Sasanian Iran, roughly between 200 and 700 CE. An example is the Harbaqa dam, found in contemporary Syria, which was one of the largest dams in the region before the advent of contemporary dams, although the date of the construction of the dam is still contested, likely at some point between 300 and 750 CE [63,64]. It is a gravity dam $345 \mathrm{~m}$ in length, $20.5 \mathrm{~m}$ in height, and it is $18 \mathrm{~m}$ wide at the base, built to impound water diverted off of the Wadi al-Barda. The base of the dam was made especially wide to counteract horizontal pressure from sudden floods [63]. Three separate outlets were created for this dam over time, two of which appear to have silted immediately, and a third was created in response to this infill of sediment. As with systems with so much capacity for 
latent sediment storage, there is no evidence of its inoperability due to sedimentation apart from the evidence of the outlets - it was used almost continuously until the present, when sediments finally reached the height of the dam. The silts accumulated behind the dam are now actively cultivated.

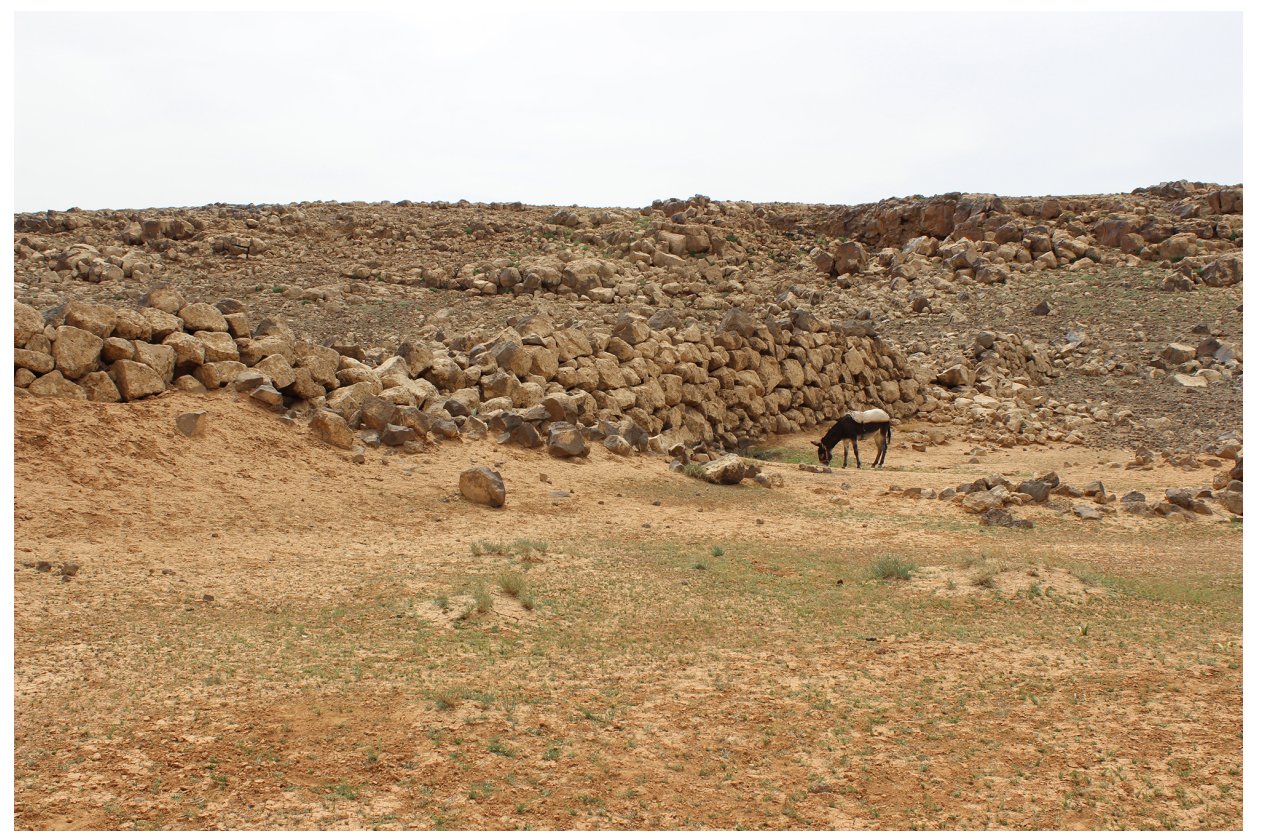

Figure 3. The Jawa dam, with the interior of the dam facing the viewer. Note the donkey for scale.

(C) Bernd Müller-Neuhof (DAI-Orientabteilung), used by permission.

In comparison, in the northeast of Iran near the contemporary city of Gorgan, and close to the border of Turkmenistan, a nearly 700 m-long earthen dam was constructed between 500 and 600 CE, during the period of the Sasanian Empire and roughly contemporaneous with the Harbaqa dam. This dam spanned a portion of the Gorgan valley to supply water to numerous feeder canals for irrigating large agricultural plots near an active military frontier. Despite its massive size, it is clear that this was an expedient construction, as it was likely breached at some point early in its life due to rapid sediment accumulation. The latter is identifiable by the lack of sedimentation in basins upstream of the dam, and it appears that bedload was permitted to flow directly into the reservoir itself [65]. Canals were built to divert water at the highest point of the reservoir, thereby avoiding the sediments that accumulated at the base of the dam and providing filtered water down the system, but did not offer any way to sustainably manage the sediments that accumulated at the base of the dam [66]. As a result, there is no evidence of any use of the dam beyond its short life in association with this military frontier.

While there are numerous other examples from across the world of both successful and unsuccessful ancient dams (see especially $[19,31]$ ), a nearby analogue with a different monsoonal climate is the Sanchi dam complex located in contemporary Madhya Pradesh, central India. Sixteen separate dams have been identified that date between the second century BCE to the fifth century CE, with heights between $1 \mathrm{~m}$ to $6 \mathrm{~m}$, and lengths from $80 \mathrm{~m}$ to $1.5 \mathrm{~km}$, impounding well over a million cubic meters of water $[67,68]$. All of these dams appear to be associated with an ancient Buddhist monastic site, and provided water for both human and animal consumption, with some irrigation of cultivated fields [69]. Intriguingly, the reason for the ultimate failures of some of these dams was flood damage from rapid discharge due to monsoonal precipitation patterns, rather than sedimentation. Inscriptions from south India during this period mention the payment for regular de-sedimentation of large reservoirs, which may analogize to some degree to the Sanchi area, which may have also maintained an effective labor pool for removing accumulated sediments [70]. There are other contemporaneous 
dams and reservoirs in Sri Lanka which illustrate similar principles of construction to those found on the subcontinent, especially with respect to spillways to control floodwaters [71].

\section{Conclusions and Future Directions}

While water supply around the world has been revolutionized by technological developments such as the tube well and centrifugal pump (with depletion of groundwater supplies as a result in some cases), many contemporary societies with developed economies still depend on reservoirs to supply water, and water supply is essential to societal well being, even if the cost of this water is a small part of the overall economy. As observed by Annandale [7], this storage is being progressively lost to sedimentation: total water storage in reservoirs has been decreasing (from sedimentation) faster than new reservoir storage has been built (Figure 4) [7].

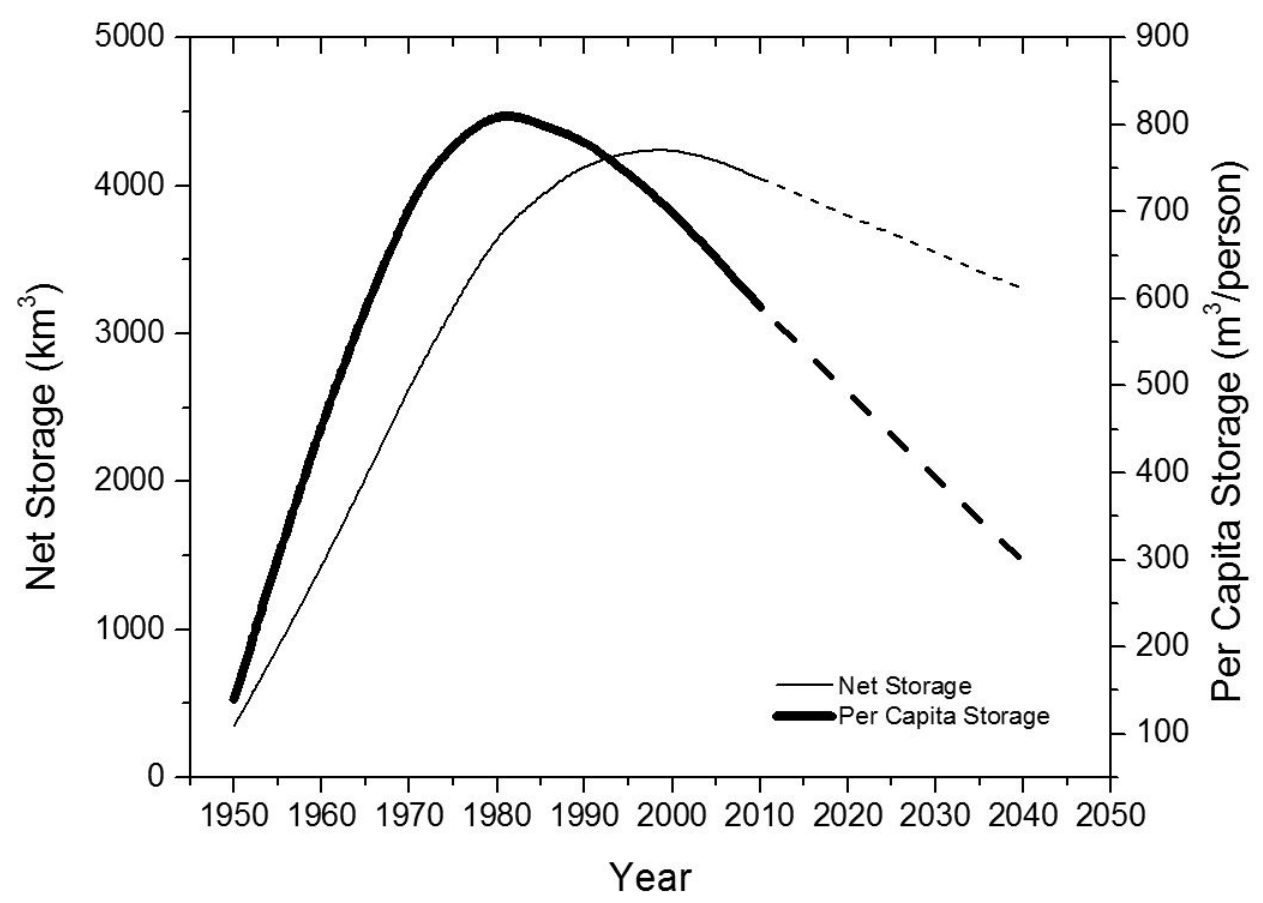

Figure 4. Changes in total and per capita global water storage, projected to 2040, showing losses to sedimentation exceeding new capacity. Source: [7], used by permission.

As we have tried to demonstrate in this paper, sedimentation problems have occurred in water-supply infrastructure for as long as humans have built such infrastructure. Societies have responded to the inevitability of sedimentation in different ways. In some cases, such as the canals built by some communities in southern Mesopotamia to divert water from rivers, "it was easier to abandon these canals and build new ones" than to maintain the canals by removing accumulated sediment [18]. This is essentially the approach now being taken with respect to dams in most of the world today, which are designed with a 50-100-year "design life", and without consideration of what happens after that. As observed by Annandale et al. [6],

“Dams have traditionally been designed under the 'design life' paradigm, which entails estimation of the sedimentation rate and trap efficiency, and provision of a sediment storage pool volume equivalent to the design life (typically 50 or 100 years). Under this paradigm, consequences beyond the design life are not addressed, leading to decommissioning. In many regions, however, new reservoirs are both costly and difficult to construct because the best (least costly) dam sites have already been used, and because there is intense 
resistance to the flooding of additional lands due to competing land uses and social and environmental concerns. The cost of dam decommissioning may also be very high."

As documented by Zarfl et al. [72], "[a]t least 3700 major dams, each with a capacity of more than $1 \mathrm{MW}$, are either planned or under construction, primarily in countries with emerging economies." Very few of these new dams are designed to sustainably manage sediment, so the dams can be seen as the modern-day equivalents of some of the water supply structures mentioned previously: expedient technology rather than infrastructure designed to function sustainably. This approach is short-sighted, because once the best reservoir sites are constructed, they are used up, and subsequent dams will be in less favorable sites, and thus less efficient and more prone to problems. As discussed above, there are strategies to sustainably manage sediment that can be applied to many reservoirs, but they are rarely implemented today. It is instructive to realize that communities in the drylands of the Mediterranean and beyond implemented sediment management techniques that allowed for the sustained use of water dams and diversions over centuries.

Considering ancient water management strategies from a sediment-sustainability perspective, we can see that some systems required more frequent maintenance (clearing of sediment) than others. Dams and reservoirs were larger systems and required relatively less-frequent maintenance. However, even the larger dams in the ancient world (plotting on the lower-right end of the x-axis in Figure 5) would rank as small systems today, which suggests an insight into why it has been possible for 20th century dam developers to ignore sedimentation in reservoirs in most cases. The long period over which most modern reservoirs can accumulate sediment before they require maintenance, combined with the short-term economic analysis that drives reservoir design, allows dam developers to stay in denial about the reality of sedimentation, putting the problem off to future generations. While we do not mean to imply that all dams should function indefinitely over the centuries, the record from past communities reminds us that sedimentation must be addressed for water supply systems to be sustainable over time. We hope in this paper to encourage a longer temporal view of the question, one that would go beyond the 50-100 years usually considered as the dam's "design life".

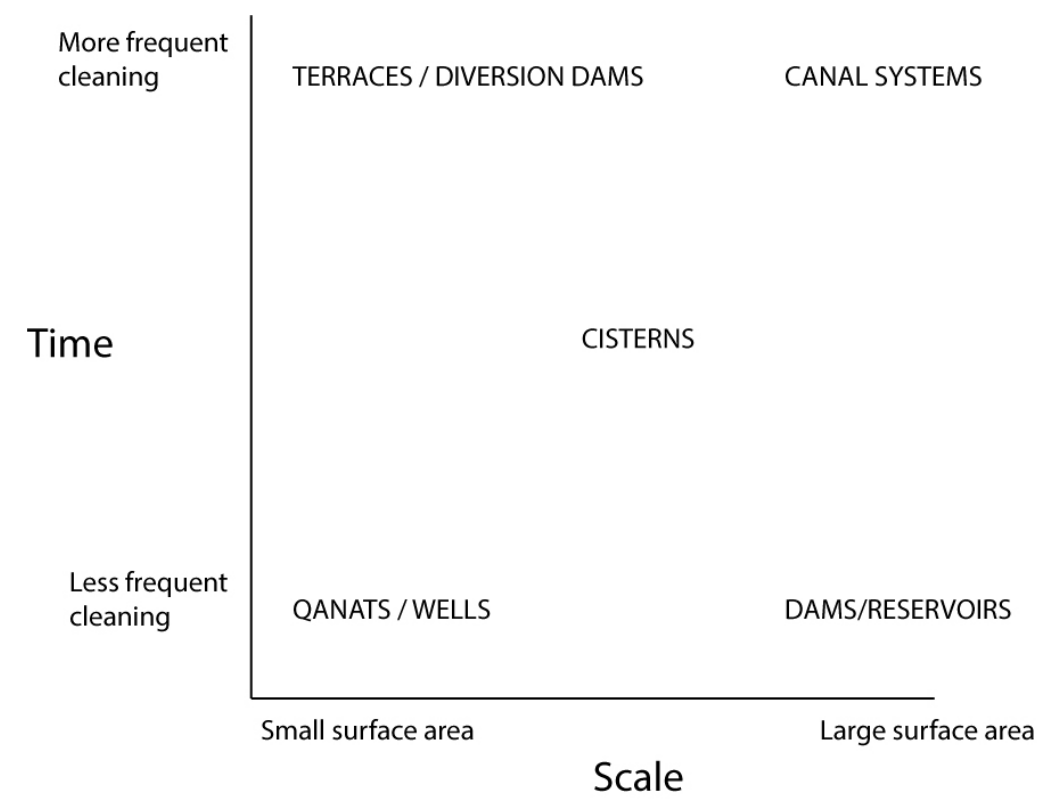

Figure 5. Schematic representation of the relationship of time and scale, with various kinds of water supply structures depicted. 
Acknowledgments: This study was undertaken as part of the interdisciplinary faculty seminar, Water Management: Past and Future Adaptation, hosted from 2011-2016 within the Institute of International Studies of the University of California Berkeley. We benefited greatly from sharing ideas with other participants in the seminar, and we gratefully acknowledge the support of the Institute for this research. The authors also gratefully acknowledge the Collegium de Lyon-Institut des Etudes Avancées de l'Université de Lyon, the EURIAS Fellowship Programme and the European Commission (Marie-Sklodowska-Curie Actions-COFUND Programme-FP7) for support of manuscript preparation by Kondolf. The manuscript was greatly improved thanks to the comments of the editor and two anonymous reviewers.

Author Contributions: A.F. and G.M.K. conceived and conducted the research and shared the writing.

Conflicts of Interest: The authors declare no conflict of interest.

\section{References}

1. Hick, D.; Gomez, B. Sediment Transport. In Tools in Fluvial Geomorphology; Kondolf, G., Piegay, H., Eds.; John Wiley \& Sons: New York, NY, USA, 2016; pp. 323-356.

2. Kondolf, G.M. Hungry water: Effects of dams and gravel mining on river channels. Environ. Manag. 1997, 21, 533-551.

3. Brune, G.M. Trap Efficiencies of Reservoirs. Trans. AGU 1953, 33, 407-418.

4. Walter, R.C.; Merritts, D.J. Natural streams and the legacy of water-powered mills. Science 2008, 319, $299-304$.

5. Morris, G.; Fan, J. Reservoir Sedimentation Handbook: Design and Management of Dams, Reservoirs and Watersheds for Sustainable Use; McGraw-Hill Book Co.: New York, NY, USA, 1998.

6. Annandale, G.W.; Morris, G.L.; Karki, P. Extending the Life of Reservoirs: Sustainable Sediment Management for Dams and Run-of-River Hydropower; The World Bank Group: Washington, DC, USA, 2016.

7. Annandale, G.W. Quenching the Thirst: Sustainable Watter Supply and Climate Change; CreateSpace: North Charleston, SC, USA, 2013.

8. Deitch, M.J.; Goodfellow, M.J.; Feirer, S.T. Characterizing Precipitation Variability and Trends in the World's Mediterranean-Climate Areas. Water 2017, 9, 259.

9. George, M.W.; Hotchkiss, R.H.; Huffaker, R. Reservoir Sustainability and Sediment Management. J. Water Resour. Plan. Manag. 2017, 143, doi:10.1061/(ASCE)WR.1943-5452.0000720.

10. Wang, H.W.; Kondolf, G.M. Upstream Sediment-Control Dams: Five Decades of Experience in the Rapidly Eroding Dahan River Basin, Taiwan. J. Am. Water Resour. Assoc. 2014, 50, 745-747.

11. Minear, J.T.; Kondolf, G.M. Estimating reservoir sedimentation rates at large spatial and temporal scales: A case study of California. Water Resour. Res. 2009, 45, doi:10.1029/2007WR006703.

12. Smith, N. A History of Dams; The Citadel Press: Secaucus, NJ, USA, 1972.

13. McHenry, J. Reservoir sedimentation. Water Resour. Bull. 1974, 10, 329-337.

14. Wang, Z.Y.; Hu, C. Strategies for managing reservoir sedimentation. Int. J. Sedim. Res. 2009, 24, 369-384.

15. Sumi, T.; Kantouch, S.; Suzuki, S. Performance of Miwa Dam sediment bypass tunnel: Evaluation of upstream and downstream state and bypassing efficiency. ICOLD Congr. 2012, 24, 576-596.

16. Kondolf, G.M.; Gao, Y.; Annandale, G.W.; Morris, G.L.; Jiang, E.; Zhang, J.; Cao, Y.; Carling, P.; Fu, K.; Guo, Q.; et al. Sustainable sediment management in reservoirs and regulated rivers: Experiences from five continents. Earth's Future 2014, 2, 256-280.

17. Kantoush, S.; Sumi, T. RIver Morphology and Sediment Management Strategies for Sustainable Reservoir in Japan and European Alps; No. 53B; Annuals of Disaster Prevention Research Institute, Kyoto University: Kyoto, Japan, 2010.

18. Mays, L.W. Ancient Water Technologies; Springer: Dordrecht, The Netherlands, 2010.

19. Scarborough, V.L. Flow of Power: Ancient Water Systems and Landscapes; SAR Press: Santa Fe, NM, USA, 2003.

20. Finlayson, B.; Lovell, J.; Smith, S.; Mithen, S. The archaeology of water management in the Jordan Valley from the Epipalaeolithic to the Nabataean, 21,000 BP (19,000 BC) to AD 106. In Water, Life, and Civilisation: Climate, Environment and Society in the Jordan Valley; Cambridge University Press: Cambridge, UK, 2011; pp. 191-217.

21. Miller, R. Water Use in Syria and Palestine from the Neolithic to the Bronze Age. World Archaeol. 1980, 11, 331-341.

22. Scarborough, V.L. Water management adaptations in nonindustrial complex societies: An archaeological perspective. Archaeol. Method Theory 1991, 3, 101-154. 
23. Braemer, F.; Genequand, D.; Maridat, C.D.; Blanc, P.M.; Dentzer, J.M.; Gazagne, D.; Wech, P. Long-term management of water in the Central Levant: The Hawran case (Syria). World Archaeol. 2009, 41, 36-57.

24. Mithen, S. The domestication of water: Water management in the ancient world and its prehistoric origins in the Jordan Valley. Philos. Trans. R. Soc. Lond. A Math. Phys. Eng. Sci. 2010, 368, 5249-5274.

25. Barton, C.M.; Ullah, I.I.; Bergin, S. Land use, water and Mediterranean landscapes: Modelling long-term dynamics of complex socio-ecological systems. Philos. Trans. R. Soc. Lond. A Math. Phys. Eng. Sci. 2010, $368,5275-5297$.

26. Hodge, A.T. Reservoirs and Dams. In Handbook of Ancient Water Technology; Wikander, O., Ed.; Brill: Leiden, The Netherlands, 2000; pp. 331-342.

27. Kamash, Z. Archaeologies of Water in the Roman Near East: 63 BC-AD 636; Gorgias Press: Piscataway, NJ, USA, 2010.

28. Kamash, Z. An exploration of the relationship between shifting power, changing behaviour and new water technologies in the Roman Near East. Water Hist. 2012, 4, 79-93.

29. Wilkinson, T.; Rayne, L.; Jotheri, J. Hydraulic landscapes in Mesopotamia: The role of human niche construction. Water Hist. 2015, 7, 397-418.

30. Casana, J. Structural transformations in settlement systems of the northern Levant. Am. J. Archaeol. 2007, 111, 195-221.

31. Scarborough, V. An Overview of Mesoamerican Water Systems. In Precolumbian Water Management; Lucero, L.J., Fash, B.W., Eds.; University of Arizona Press: Tucson, AZ, USA, 2006; pp. 223-234.

32. Roberts, N.; Meadows, M.E.; Dodson, J.R. The history of mediterranean-type environments: Climate, culture and landscape. Holocene 2001, 11, 631-634.

33. Roberts, N.; Stevenson, T.; Davis, B.; Cheddadi, R.; Brewster, S.; Rosen, A. Holocene climate, environment and cultural change in the circum-Mediterranean region. In Past Climate Variability Through Europe and Africa; Springer: Dordrecht, The Netherlands, 2004; pp. 343-362.

34. Jalut, G.; Dedoubat, J.J.; Fontugne, M.; Otto, T. Holocene circum-Mediterranean vegetation changes: Climate forcing and human impact. Quat. Int. 2009, 200, 4-18.

35. Wittfogel, K.A. Oriental Despotism: A Comparative Study of Total Power; Yale University Press: New Haven, CT, USA, 1957.

36. Adams, R.M. Land behind Baghdad: A History of Settlement on the Diyala Plains; University of Chicago Press: Chicago, IL, USA, 1965.

37. Harrower, M.J. Is the hydraulic hypothesis dead yet? Irrigation and social change in ancient Yemen. World Archaeol. 2009, 41, 58-72.

38. Stanish, C. The hydraulic hypothesis revisited: Lake Titicaca Basin raised fields in theoretical perspective. Lat. Am. Antiq. 1994, 5, 312-332.

39. Davies, M.I. Wittfogel's dilemma: Heterarchy and ethnographic approaches to irrigation management in Eastern Africa and Mesopotamia. World Archaeol. 2009, 41, 16-35.

40. Mitchell, W.P. The hydraulic hypothesis: A reappraisal. Curr. Anthropol. 1973, 14, 532-534.

41. Price, D.H. Wittfogel's neglected hydraulic/hydroagricultural distinction. J. Anthropol. Res. 1994, 50, 187-204.

42. Bray, T.L. Water, Ritual, and Power in the Inca Empire. Lat. Am. Antiq. 2013, 24, 164-190.

43. Garfinkel, Y.; Vered, A.; Bar-Yosef, O. The domestication of water: The Neolithic well at Sha'ar Hagolan, Jordan Valley, Israel. Antiquity 2006, 80, 686-696.

44. Müller-Neuhof, B. The Chalcolithic/Early Bronze Age Hillfort Phenomenon in the Northern Badia. Near East. Archaeol. 2017, 80, 124-131.

45. Wilkinson, T.J.; Rayne, L. Hydraulic landscapes and imperial power in the Near East. Water Hist. 2010, 2, 115-144.

46. Lightfoot, D.R. Syrian qanat Romani: history, ecology, abandonment. J. Arid Environ. 1996, 33, 321-336.

47. English, P.W. Qanats and lifeworlds in Iranian plateau villages. Transform. Middle East. Nat. Environ. Bull. Ser. 1998, 103, 187-205.

48. Costanza, R.; Graumlich, L.; Steffen, W.; Crumley, C.; Dearing, J.; Hibbard, K.; Leemans, R.; Redman, C.; Schimel, D. Sustainability or collapse: What can we learn from integrating the history of humans and the rest of nature? Ambio A J. Hum. Environ. 2007, 36, 522-527.

49. Beckers, B.; Berking, J.; Schütt, B. Ancient water harvesting methods in the drylands of the Mediterranean and Western Asia. eTopoi J. Anc. Stud. 2013, 2, 145-164. 
50. Cressey, G.B. Qanats, karez, and foggaras. Geogr. Rev. 1958, 48, 27-44.

51. English, P.W. The origin and spread of qanats in the Old World. Proc. Am. Philos. Soc. 1968, 112, 170-181.

52. Mostafaeipour, A. Historical background, productivity and technical issues of qanats. Water Hist. 2010, 2,61-80.

53. Magee, P. The chronology and environmental background of Iron Age settlement in Southeastern Iran and the question of the origin of the Qanat irrigation system. Iran. Antiq. 2005, 40, 217-231.

54. Ortlof, C.R. The Water Supply and Distribution System of the Nabataean City of Petra (Jordan), 300 BC-AD 300. Camb. Archaeol. J. 2005, 15, 93-109.

55. Mays, L.W. A brief history of water technology during antiquity: Before the Romans. In Ancient Water Technologies; Mays, L.W., Ed.; Springer: New York, NY, USA, 2010; pp. 1-28.

56. Helms, S.W. Jawa: Lost City of the Black Desert; Methuen \& Co. Ltd.: London, UK, 1989.

57. Whitehead, P.; Smith, S.; Wade, A.; Mithen, S.; Finlayson, B.; Sellwood, B.; Valdes, P. Modelling of hydrology and potential population levels at Bronze Age Jawa, Northern Jordan: A Monte Carlo approach to cope with uncertainty. J. Archaeol. Sci. 2008, 35, 517-529.

58. Meister, J.; Rettig, R.; Schütt, B. Ancient runoff agriculture at Early Bronze Age Jawa (Jordan): Water availability, efficiency and food supply capacity. J. Archaeol. Sci. Rep. 2016, doi:10.1016/j.jasrep.2016.06.033.

59. Müller-Neuhof, B.; Betts, A.; Wilcox, G. Jawa, Northeastern Jordan: The First ${ }^{14} \mathrm{C}$ Dates for the Early Occupation Phase. Z. Orient-Archäol. 2015, 8, 124-131.

60. Roberts, N. Water conservation in ancient Arabia. In Proceedings of the Seminar for Arabian Studies, Cambridge, UK, 12-14 July 1977; pp. 134-146.

61. Braemer, F.; Geyer, B.; Castle, C.; Abdulkarim, M. Conquest of new lands and water systems in the western Fertile Crescent. Water Hist. 2010, 2, 91-114.

62. Murray, W.M. The ancient dam of the Mytikas valley. Am. J. Archaeol. 1984, 88, 195-203.

63. Genequand, D. Some Thoughts on Qasr al-Hayr al-Gharbi, its Dam, its Monastery and the Ghassanids. Levant 2006, 38, 63-84.

64. Kamash, Z. Irrigation technology, society, and environment in the Roman Near East. J. Arid Environ. 2012, $86,65-74$.

65. Sauer, E.W.; Omrani Rekavandi, H.; Wilkinson, T.J.; Nokandeh, J. Persia's Imperial Power in Late Antiquity: The Great Wall of Gorgan and Frontier Landscapes of Sasanian Iran; Oxbow Books: Oxford, UK, 2013.

66. Nokandeh, J.; Sauer, E.W.; Rekavandi, H.O.; Wilkinson, T.; Abbasi, G.A.; Schweninger, J.L.; Mahmoudi, M.; Parker, D.; Fattahi, M.; Usher-Wilson, L.S.; et al. Linear barriers of northern Iran: The great wall of Gorgan and the wall of Tammishe. Iran 2006, 44, 121-173.

67. Shaw, J.; Sutcliffe, J. Ancient irrigation works in the Sanchi area: An archaeological and hydrological investigation. South Asian Stud. 2001, 17, 55-75.

68. Sutcliffe, J.; Lloyd-Smith, L.; Schwenninger, J.L.; Chauhan, M.; Misra, O.; Harvey, E. Ancient irrigation and Buddhist history in Central India: Optically stimulated luminescence dates and pollen sequences from the Sanchi Dams. Asian Perspect. 2007, 46, 166-201.

69. Shaw, J.; Sutcliffe, J. Ancient dams and Buddhist landscapes in the Sanchi area: New evidence on irrigation, land use and monasticism in central India. South Asian Stud. 2005, 21, 1-24.

70. Shaw, J.; Sutcliffe, J. Water management, patronage networks and religious change: New evidence from the Sanchi dam complex and counterparts in Gujarat and Sri Lanka. South Asian Stud. 2003, 19, 73-104.

71. Bauer, A.M.; Morrison, K.D. Water management and reservoirs in India and Sri Lanka. In Encyclopaedia of the History of Science, Technology, and Medicine in Non-Western Cultures; Springer: Dordrecht, The Netherlands, 2016; pp. 4376-4385.

72. Zarfl, C.; Lumsdon, A.E.; Berlekamp, J.; Tydecks, L.; Tockner, K. A global boom in hydropower dam construction. Aquat. Sci. 2015, 77, 161-170.

(C) 2018 by the authors. Licensee MDPI, Basel, Switzerland. This article is an open access article distributed under the terms and conditions of the Creative Commons Attribution (CC BY) license (http:/ / creativecommons.org/licenses/by/4.0/). 